\title{
Pengaruh Variasi Waktu Peleburan Terhadap Konduktivitas Listrik Zeolit dari Abu Dasar Batubara yang Disintesis dengan Metode Peleburan Alkali Hidrotermal
}

\author{
Nurhabibah, Afdhal Muttaqin \\ JurusanFisika FMIPA UniversitasAndalas, Padang \\ Kampus Unand Limau Manis, Pauh, Padang 25163 \\ e-mail: nurhabibah967@gmail.com
}

\begin{abstract}
ABSTRAK
Telah dilakukan sintesis zeolit dari abu dasar batubara menggunakan metode peleburan alkali hidrotermal dengan variasi waktu peleburan.Variasi waktu peleburan yang digunakan adalah 1 jam (Z1), 2 jam (Z2), 3 jam (Z2), dan 4 jam (Z4). Abu dasar dan $\mathrm{NaOH}$ dilebur dengan perbandingan 1:1,2. Sampel yang telah dilebur, kemudiandipanaskanmelalui proses hidrotermal dengan medium kristalisasi $\mathrm{NaAlO}_{2}$. Sampel zeolit kemudian dinetralkan dengan aquades hingga mencapai $\mathrm{pH}$ 9-10. Sampel dikarakterisasi menggunakan XRD dengan software Match! 3. Konduktivitas listrik sampel diukur dengan LCR-meter. Hasil XRD menunjukkan bahwa sampel Z1 mengandung sodalit, lazurit, katoit, megakalsilit serta masih terdapat kuarsa dan kristobalit. Sampel Z2 mengandung sodalit, leusit dan kalsilit. Sampel Z3 mengandung sodalit dan bohmit, serta sampel Z4 mengandung sodalit, nosean dan katoit. Konduktivitas listrik yang dihasilkan berkisar dari $0,8 \times 10^{-6}-2,4 \times 10^{-6} \mathrm{~S} / \mathrm{cm}$ dan berada pada rentang bahan semikonduktor. Zeolit dengan waktu peleburan selama 2 jam mempunyai konduktivitas listrik tertinggi yaitu $2,4 \times 10^{-6} \mathrm{~S} / \mathrm{cm}$.

Kata kunci: abudasar, hidrotermal, konduktivitas, nosean, sodalit, zeolit
\end{abstract}

\section{ABSTRACT}

Synthesis of zeolites from bottom ash using alkali melting hydrothermal method by varying of melting time had been done. Melting time was varied for 1 hour (Z1), 2 hours (Z2), 3 hours (Z3) and 4 hours (Z4). Bottom ash and NaOH were melted at a ratio of 1: 1.2. The samples were melted and then heated through a hydrothermal process with $\mathrm{NaAlO}_{2}$ crystallization medium. Synthesized zeolite samples were then neutralized with distilled water until pH 9-10. The sample werecharacterized using XRD and analyzed using Match! 3 software.Electrical conductivity of the sample measured using LCR-meter. XRD results show that $Z 1$ sample contains sodalite, lazurite, katoite, megacalsilite and still have quartz and cristobalite contents. Z2 contains sodalite, leucite and calsilite. Z3 contains sodalite and bohmite, and sample Z4 contains sodalite, nosean, and katoite. The electrical conductivity of thesamples ranges from $0,8 \times 10^{-6}-2,4 \times 10^{-6} \mathrm{~S} / \mathrm{cm}$ and that is in the range of semiconductor materials. Zeolites with 2 hours of melting time has the highest electrical conductivity that is $2,4 \times 10^{-6} \mathrm{~S} / \mathrm{cm}$.

Keywords: bottom ash, hydrotermal,conductivity, nosean, sodalitezeolite

\section{PENDAHULUAN}

Zeolit adalah kristal alumina silika tetrahedral dengan struktur kerangka tiga dimensi yang mengandung kanal-kanal dan rongga-rongga berisi ion logam, biasanya terdiri dari alkali atau alkali tanah dan molekul air (Chetam, 1992 ; Hamdan, 1992)). Zeolit tergolong dalam material nanopori dengan ukuran pori antara $0,3-1,5 \mathrm{~nm}$, sehingga dapat dimanfaatkan sebagai adsorben, penukar ion, dan katalis (Aurbach, dkk., 2003). Selain itu, zeolit juga dapat dimanfaatkan sebagai material semikonduktor pada piranti elektronika (Kalogeras dan Dova, 1998). Berdasarkan proses terbentuknya, zeolit dapat dibedakan menjadi dua, yaitu : zeolit alam dan sintetis. Zeolit alam terbentuk secara alamiah di alam, sedangkan zeolit sintetis dibuat dari bahan yang mengandung komponen dasar alumina dan silika.

Zeolit sintetis dapat dibuat dengan menggunakan bahan abu dasar sisa pembakaran batubara. Sari (2016) menyatakan bahwa abu dasar batubara dari Pembangkit Listrik Tenaga Uap (PLTU) Ombilin di Sawahlunto memiliki komposisi utama yaitu alumina $\left(\mathrm{Al}_{2} \mathrm{O}_{3}\right)$ sebesar 33,172\% dan silika $\left(\mathrm{SiO}_{2}\right)$ 57,236\%. Kandungan alumina dan silika pada abu dasar memiliki kesamaan dengan senyawa penyusun zeolit, sehingga abu dasar dapat dimanfaatkan untuk mensintesis zeolit.

Bahan dasar yang sama (abu dasar batubara) dapat menghasilkan zeolit sintetis yang berbeda tergantung pada metode sintesis, aktivator, dan medium kristalisasi. Waleza dan 
Muttaqin (2015) menghasilkan zeolit Na-X dan Na-P dengan menggunakan metode refluks. Nikmah (2008) melakukan sintesis zeolit dari abu dasar dengan metode hidrotermal dan menghasilkan zeolit A. Lestari dan Muttaqin (2015) mendapatkan zeolit Na-X ketika menggunakan abu dasar dengan metode alkali hidrotermal dengan media kristalisasi air laut. Sari (2016) mendapatkan zeolit Na-P, sodalit, dan philipsite dengan menggunakan metode peleburan diikuti dengan sonikasi alkali hidrotermal. Sriwahyuni (2014) mendapatkan zeolit tipe $\mathrm{Na}$ dengan metode peleburan alkali hidrotermal dan natrium hidroksida $(\mathrm{NaOH})$ sebagai aktivator, dan aquades sebagai media kristalisasi. Selain itu juga didapatkan zeolit tipe Na-A, zeolit $\mathrm{P}$ dan unnamed zeolite ketika menggunakan natrium aluminat $\left(\mathrm{NaAlO}_{2}\right)$ sebagai media kristalisasi. Sayangnya zeolit yang disintesis oleh Sriwahyuni (2014), masih memiliki fase amorf (kuarsa) yang dapat diubah menjadi zeolit.

Metode hidrotermal langsung memiliki kelemahan diantaranya kristalisasi yang lambat dan tingkat kemurnian zeolit yang masih rendah (Belviso, 2009 ; Londar dkk., 2010). Peleburan sebelum reaksi hidrotermal menghasilkan zeolit dengan kristalinitas yang lebih tinggi serta waktu kristalisasi yang lebih singkat (Yanti, 2009). Prinsip dasar metode peleburan adalah mereaksikan bahan dasar dengan basa alkali seperti $\mathrm{NaOH}$ pada suhu tinggi. Peleburan bertujuan untuk merubah komponen silika dan alumina yang sebagian besar dalam bentuk kuarsa menjadi natrium silikat dan natrium alumina yang merupakan spesies reaktif untuk sintesis zeolit. Pada tahap peleburan ini juga terjadi proses dissolution yaitu proses pelepasan komponen $\mathrm{Si}$ dan $\mathrm{Al}$ terjadi karena adanya pengaruh penambahan basa alkali seperti kalium hidroksida $(\mathrm{KOH})$ atau $\mathrm{NaOH}$ pada abu dasar (Bukhari, dkk., 2014). Proses dissolution dipengaruhi oleh aktivator, temperatur dan waktu peleburan. Waktu peleburan mempengaruhi proses terbentuknya zeolit dalam membuka pori dari abu dasar yang akan disintesis menjadi zeolit sehingga membantu menghilangkan pengotor - pengotor oksida.

Konduktivitas listrik zeolit naik dengan meningkatnya kristalinitas zeolit. Konduktivitas zeolit dari abu dasar bergantung pada media kristalisasi. Sriwahyuni (2014) menemukan bahwa konduktivitas listrik zeolit meningkat dengan penambahan natrium aluminat $\left(\mathrm{NaAlO}_{2}\right)$ sebagai media kristalisasi.

Tujuan penelitian ini adalah melihat pengaruh variasi waktu peleburan terhadap jenis zeolit yang dihasilkan dan mendapatkan waktu yang optimal untuk menghasilkan zeolit dengan kemurnian yang tinggi. Selain itu penelitian ini juga melihat bagaimana nilai konduktivitas listrik zeolit yang dihasilkan sehingga dapat dimanfaatkan dalam berbagai aplikasi.

\section{METODE}

\subsection{Teknik Penelitian}

\subsubsection{Sintesis Zeolit}

Zeolit disintesis dengan metode peleburan alkali hidrotermal (Sriwahyuni, 2014). Abu dasar yang berasal dari PLTU Ombilin Sawahlunto tersebut dikeringkan terlebih dahulu, kemudian dihaluskan dan diayak dengan ayakan 200 mesh untuk mendapatkan ukuran yang lebih seragam. $150 \mathrm{~g}$ abu dasar dipanaskan di dalam oven pada suhu $105{ }^{\circ} \mathrm{C}$ untuk menghilangkan unsur air, lalu didinginkan dalam desikator. $12 \mathrm{~g}$ abu dasar yang telah kering dan $14 \mathrm{~g} \mathrm{NaOH}$ dihaluskan, dicampur dan kemudian dihomogenkan. Percampuran ini dibuat 4 buah sampel yang akan diberi perlakuan berbeda. Sampel ini kemudian dilebur dengan cara dipanaskan di dalam furnace dengan suhu $750{ }^{\circ} \mathrm{C}$ dengan variasi waktu selama 1 jam, 2 jam, 3 jam dan 4 jam. Sampel kemudian didinginkan dan dihaluskan. Masing-masing sampel dilarutkan dengan $250 \mathrm{ml}$ aquabidestilat.

Sampel diaduk dengan menggunakan magnetic stirrer selama 1 jam. Setelah diaduk, sampel dimasukkan ke dalam botol polietilen dan di-aging selama 2 jam pada temperatur 30 ${ }^{\circ} \mathrm{C}$, kemudian sampel disaring dengan menggunakan kertas saring, dan diambil ekstraknya. Ekstrak sampel hasil penyaringan dilarutkan dalam $50 \mathrm{ml}$ larutan $\mathrm{NaAlO}_{2}$ yang telah disiapkan terlebih dahulu. Selanjutnya sampel dimasukkan ke dalam reaktor hidrotermal (teflon autoclave) lalu dimasukkan ke dalam oven dengan pengaturan temperatur $100{ }^{\circ} \mathrm{C}$ (selama 12 jam). Setelah dioven, sampel dipisahkan dari filtratnya, lalu dicuci dengan aquades hingga 
mendapatkan $\mathrm{pH}$ 9-10. Setelah diperoleh $\mathrm{pH}$ yang diinginkan, sampel kemudian dikeringkan pada temperatur $105^{\circ} \mathrm{C}$ selama 24 jam, sehingga diperoleh zeolit aktif dalam bentuk serbuk.

\subsubsection{Karakterisasi Zeolit}

Karakterisasi sampel yang dilakukan meliputi karakterisasi jeis zeolit yang dihasilkan dengan menggunakan X-Ray Diffraction (XRD) dan dilakukan pengukuran konduktivitas listrik menggunakan LCR-meter. Untuk pengukuran konduktivitas listrik, 0,3 g bubuk zeolit dikompaksi dengan tekanan yang sama untuk keempat sampel. Sampel dibentuk menjadi tablet dengan diameter $12 \mathrm{~mm}$ dan ketebalan $2 \mathrm{~mm}$. Selanjutnya konduktivitas listrik diukur dengan menggunakan LCR-meter.

\section{HASIL DAN DISKUSI}

\subsection{Sintesis Zeolit dari Abu Dasar}

Proses sintesis menghasilkan zeolit berbentuk bubuk dengan massa yang bervariasi, seperti pada Tabel 1. Dari Tabel 1 terlihat bahwa dengan massa awal yang sama, hasil proses peleburan tidak berubah signifikan. Hal ini dikarenakan pada proses ini hanya terjadi pemutusan rantai-rantai Si dan $\mathrm{Al}$ yang terdapat pada abu dasar yaitu pada proses dissolution dan condensation (Bukhori dkk., 2014). Perbedaan jumlah massa akhir yang dihasilkan dari proses peleburan ini berkaitan dengan lama waktu peleburan. Pada tabel terlihat, untuk peleburan satu jam dihasilkan bubuk zeolit sebanyak 10,47 $\mathrm{g}$, dan terus meningkat hingga menghasilkan bubuk zeolit sebanyak 15,67 g untuk waktu 4 jam. Pada tahapan ini telah terbentuk bubuk zeolit, karena pada tahapan ini terjadi proses nukleasi dan pertumbuhan kristal zeolit. Semakin lama waktu peleburan, semakin banyak bubuk zeolit yg dihasilkan seperti pada sampel 4 jam mencapai lebih dari $50 \%$ massa awal.

Tabel 1 Massa sampel selama proses metode peleburan alkali hidrotermal

\begin{tabular}{ccccc}
\hline Waktupeleburan & Sampel & $\begin{array}{c}\text { Massa } \\
\text { awalpencampuran } \\
\text { abudasar + NaOH } \\
(\mathbf{g})\end{array}$ & $\begin{array}{c}\text { Massa setelah } \\
\text { proses } \\
\text { peleburan } \\
(\mathbf{g})\end{array}$ & $\begin{array}{c}\text { Massa akhirsetelah } \\
\text { proses Hidrotermal } \\
\text { (bubukzeolit) }\end{array}$ \\
\hline 1 jam & Z1 & 26,4 & 22,09 & 10,47 \\
2 jam & Z3 & 26,4 & 21,92 & 12,98 \\
3 jam & Z3 & 26,4 & 21,85 & 13,58 \\
4 jam & Z4 & 26,4 & 21,78 & 15,67 \\
\hline
\end{tabular}

Semakin meningkatnya jumlah bubuk zeolit yang dihasilkan kemungkinan dikarenakan pengotor-pengotor yang terdapat pada abu dasar semakin berkurang sehingga komponen Si dan $\mathrm{Al}$ akan lebih mudah bereaksi membentuk zeolit. Peleburan abu dasar menggunakan $\mathrm{NaOH}$ bertujuan untuk mendekomposisi komponen - komponen silika-alumina menjadi natrium silikat dan natrium aluminat sebagai spesies reaktif pembentuk zeolit (Chang dan Shih, 1998).

Selain berpengaruh terhadap jumlah massa bubuk zeolit yang dihasilkan, variasi waktu peleburan juga mempengaruhi warna dari bubuk zeolit yang dihasilkan seperti terlihat pada Gambar 1. Bubuk zeolit yang dihasilkan mengalami perubahan warna menuju ke arah putih kekuning-kuningan seiring dengan peningkatan waktu peleburan.

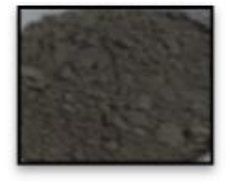

(a)

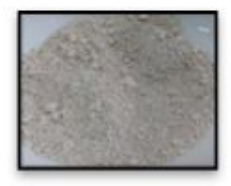

(b)

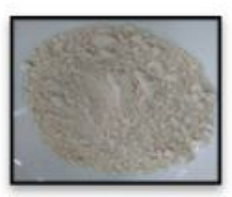

(c)

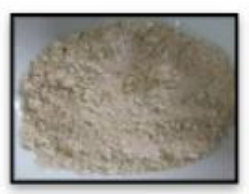

(d)

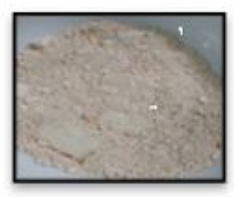

(e)

Gambar 1 Abu dasar (a) sebelum diberi perlakuan, (b) sampel Z1, (c) sampel Z2, (d) sampel Z3, (e) sampel Z4 


\subsection{Nilai Konduktivitas Listrik Zeolit Sintetis}

Semua sampel dikarakterisasi dengan XRD dan selanjutnya hasil uji XRD dianalisis menggunakan software Match! 3 sehingga didapatkan hasil seperti pada Tabel 2.Berdasarkan pada Tabel 2, zeolit yang dihasilkan pada peleburan 1 jam memiliki tingkat kemurnian yang rendah yaitu sodalit $(2,7 \%)$ dan lezurit $(47,1 \%)$, serta megakalsilit $(6,6 \%)$. Sodalit (SOD) merupakan salah satu jenis zeolit dengan struktur kristal berbentuk kubik, sedangkan lezurit masih termasuk dalam keluarga SOD dengan perbedaan pada parameter kisi. Megakalsilit sendiri merupakan zeolit dengan struktur heksagonal seperti halnya kalsilit. Pada sampel 1 jam juga dihasilkan mineral katoit (Calsium Aluminum Oxide Hydrate) yaitu mineral dengan struktur kristal kubik, namun tidak memiliki pori seperti halnya zeolit.

Tabel 2 Kandungan kristal yang diperoleh untuk variasi waktu peleburan

\begin{tabular}{lcccc}
\hline \multicolumn{1}{c}{ Produk yang } & \multicolumn{4}{c}{ WaktuPeleburan } \\
\cline { 2 - 5 } dihasilkan & $\mathbf{1}$ jam & 2 jam & 3 jam & 4 jam \\
\hline Kuarsa & $2,7 \%$ & - & - & - \\
Kristobalit & $4,2 \%$ & - & - & - \\
Megakalsilit & $6,6 \%$ & - & - & - \\
Katoit & $29,4 \%$ & - & - & $36,0 \%$ \\
Lazurit & $47,1 \%$ & - & - & - \\
Leusit & - & $34,7 \%$ & - & - \\
Kalsilit & - & $22,2 \%$ & - & - \\
Bohmit & - & - & $33,4 \%$ & - \\
Nosean & - & - & - & $56,9 \%$ \\
Sodalit & $2,7 \%$ & $43,1 \%$ & $66,6 \%$ & $7,1 \%$ \\
\hline
\end{tabular}

Perubahan yang terjadi pada sampel dengan variasi peleburan 2 jam jika dibandingkan dengan sampel 1 jam adalah menghilangnya sejumlah senyawa kuarsa dan kristobalit yang merupakan kandungan dasar abu dasar batubara. Hal ini menunjukkan bahwa peningkatan waktu peleburan berhasil merubah kuarsa dan kristobalit menjadi bentuk mineral lain. Selain sodalit, juga dihasilkan leusit $(34,7 \%)$ dan kalsilit $(22,2 \%)$ yang juga merupakan zeolit. Pada waktu peleburan 2 jam dihasilkan zeolit dengan tingkat homogenitas zeolit yang paling tinggi, yaitu menghasilkan zeolit dengan 3 jenis zeolit (sodalit, kalsilit dan leusit).

Peningkatan waktu peleburan menjadi 3 jam menunjukkan adanya perubahan dari hasilsebelumnya, seperti yang terlihat pada Tabel 2. Pada waktu peleburan 3 jam, tingkat kemurnian zeolit sodalit menjadi 66,6\%, meningkat dari sebelumnya yang hanya 2,7\% (1 jam) dan $43,1 \%$ (2 jam). Selain sodalit, terdapat mineral bohmit $\left(\mathrm{AlHO}_{2}\right) 34,4 \%$ yanghanya mengandung aluminium. Jika dilihat dari hasil akhir ini, waktu maksimum untuk memperoleh zeolit sodalit adalah pada waktu 3 jam. Namun, kekurangan Si mengakibatkan kelebihan Al berikatan dengan $\mathrm{H}_{2} \mathrm{O}$ membentuk bohmit $\left(\mathrm{AlHO}_{2}\right)$. Sodalit dengan kemurnian $100 \%$, kemungkinan dapat dilakukan dengan mengurangi konsentrasi $\mathrm{NaAlO}_{2}$ yang ditambahkan dengan menggunakan waktu peleburan selama 3 jam.

Peningkatan waktu peleburan hingga 4 jam mengakibatkan konsentrasi sodalit yang tadinya mencapai $66,6 \%$ menurun hingga $7,1 \%$ (Tabel 2). Sebagaimana diketahui, sodalit merupakan fase metastabil yang reaktif dan dapat berubah menjadi beberapa jenis zeolit lain (Xu dkk., 2007). Sodalit yang sebelumnya telah terbentuk berubah menjadi zeolit baru yaitu nosean $\left(\mathrm{Na}_{8}\left(\mathrm{Al}_{6} \mathrm{Si}_{6} \mathrm{O}_{24}\right) \mathrm{SO}_{4} \cdot \mathrm{H}_{2} \mathrm{O}\right)$ dengan kemurnian 56,9\%. Nosean adalah salah satu material hasil transformasi zeolit jenis sodalit dengan struktur kristal berbentuk kubik. Berbeda dengan sampel 2 jam dan 3 jam, katoit yang sebelumnya ada pada proses pemanasan 1 jam, muncul kembali pada proses pemanasan 4 jam ini dengan kemurnian 36,0\%.

Berdasarkan hasil XRD dari keempat sampel pada Tabel 2 dapat disimpulkan bahwa lama waktu peleburan sangat mempengaruhi tipe, kemurnian dan homogenitas zeolit yang dihasilkan. Waktu peleburan yang optimum digunakan dalam proses peleburan alkali hidrotermal adalah 3 jam. Terbukti ketika waktu peleburan dinaikkan menjadi 4 jam, kemurnian dan homogenitas zeolit yang dihasil semakin menurun. Perbedaan tingkat kemurnian dan 
homogenitas zeolit dapat mempengaruhi nilai konduktivitas zeolit yang dihasilkan.Hasil pengukuran konduktivitas masing-masing zeolit sintetis dapat dilihat pada Gambar 2. Konduktivitas listrik zeolit sintetis yang didapatkan berkisar antara $0,8 \quad 10^{-6}-2,4 \quad 10^{-6} \mathrm{~S} / \mathrm{cm}$. Nilai konduktivitas yang didapat berada pada $10^{-1}-10^{-11} \mathrm{~S} / \mathrm{cm}$ yang dapat diklasifikasikan ke dalam material semikonduktor (Kalogeras dan Dova, 1998). Sampel dengan waktu peleburan selama 2 jam memiliki konduktivitas lebih tinggi daripada sampel lainnya yaitu 2,4 $10^{-6}$ S/cm dengan frekuensi $1000 \mathrm{~Hz}$.

Perubahan nilai konduktivitas listrik terhadap waktu peleburan dapat dilihat pada Gambar 2. Pada Gambar 2 terlihat bahwa lama waktu peleburan berpengaruh terhadap nilai konduktivitas listrik dari zeolit sintetis yang dihasilkan. Secara keseluruhan dari 3 variasi frekuensi yang digunakan menghasilkan grafik dengan pola yang sama.
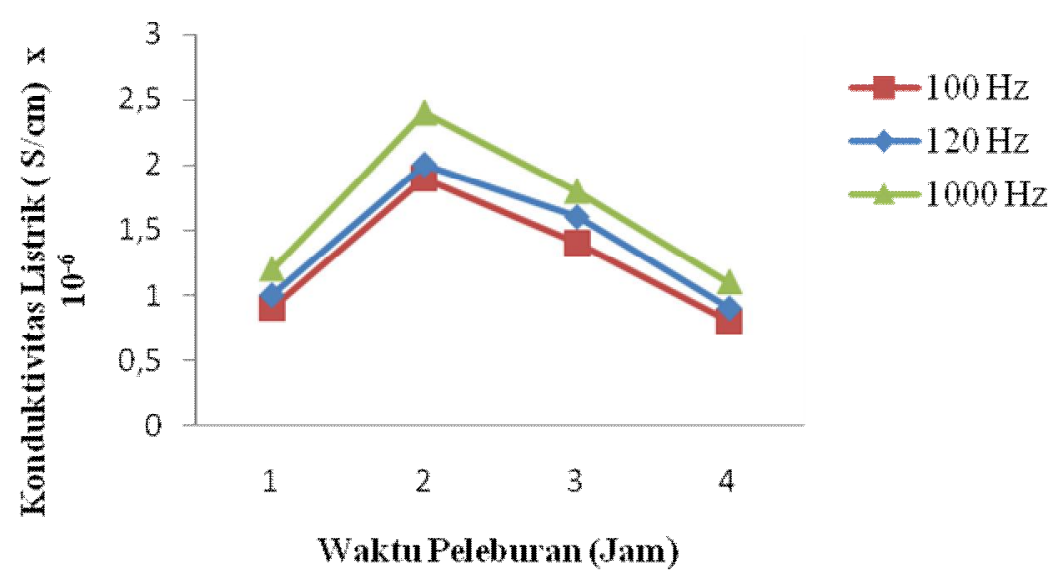

Gambar 2 Grafik hubungan waktu peleburan terhadap konduktivitas listrik zeolit sintetis pada masing-masing sampel

Pada Gambar 2 dapat dilihat bahwa nilai konduktivitas listrik yang dihasilkan zeolit sintetis dengan waktu peleburan selama 2 jam lebih baik dibandingkan dengan sampel lainnya. Hasil ini didukung dengan karakterisasi XRD pada Tabel 2 yang menunjukkan bahwa pada sampel dengan waktu peleburan selama 2 jam tidak mengandung pengotor seperti kuarsa, kristobalit dan katoit. Selain itu pada sampel 2 jam dihasilkan zeolit yang lebih banyak (sodalit, leusit, dan kalisilit).

Peningkatan waktu peleburan selama 3 dan 4 jam ternyata menurunkan tingkat konduktivitas. Pada waktu peleburan menjadi 3 jam menghasilkan zeolit dengan jenis sodalit dengan konsentrasi yang lebih murni, namun adanya mineral baru yaitu bohmit yang berbentuk kubik yang merupakan material bukan zeolit menjadikan nilai konduktivitas malah menurun. Hal ini menunjukkan bahwa tingkat homogenitas zeolit menurun yang menyebabkan tingkat konduktivitas listriknya juga berkurang. Selanjutnya pada waktu peleburan 4 jam, kemurnian zeolit sodalit menjadi menurun, namun juga memunculkan mineral baru yaitu katoit dan nosean yang berbentuk kubik. Peningkatan waktu peleburan menjadi 4 jam mengakibatkan tingkat kemurnian dan homogenitas zeolit menjadi menurun, sehingga konduktivitas listrik yang dihasilkan juga semakin berkurang. Jadi, dapat disimpulkan bahwa lamanya waktu peleburan tidak linier terhadap nilai konduktivitas.

Nilai konduktivitas juga ditentukan oleh faktor-faktor internal dari sampel zeolit. Faktor internal yang mempengaruhi nilai konduktivitas listrik zeolit sintetis yang dihasilkan lebih pada: jenis pembawa muatan, jumlah pembawa muatan, mobilitas pembawa muatan, kemurnian, jarak antar atom, luas permukaan dan lain-lain (Smallman dan Bishop, 2000).

Pada Gambar 3 juga dapat dilihat bahwa konduktivitas listrik zeolit sintetis meningkat dengan semakin besarnya nilai frekuensi pada saat pengukuran. Hasil ini mempunyai kesamaan dengan hasil yang diperoleh oleh Sriwahyuni (2014) dan Izci dan Izci (2007) yang melakukan karakterisasi konduktivitas listrik dari zeolit Na-Y dan memperoleh nilai konduktivitas zeolit meningkat dengan semakin meningkatnya frekuensi. Frekuensi mempengaruhi konduktivitas 
akibat adanya gejala vibrasi dari atom-atom zeolit yang berkesesuaian dengan frekuensi yang diaplikasikan pada saat proses pengukuran. Vibrasi ini cenderung membuat aktivitas pembawa muatan menjadi meningkat sehingga menjadikan konduktivitas menjadi tinggi.

Penambahan kation $\mathrm{Na}^{+2}$ dari larutan $\mathrm{NaAlO}_{2}$ pada proses pembuatan zeolit dapat menstabilkan unit-unit pembentuk kerangka zeolit (Ojha,2004). Penambahan ion aluminium dari penambahan larutan $\mathrm{NaAlO}_{2}$ menyebabkan zeolit lebih bermuatan (mengandung kation). Semakin tinggi pertukaran kation pada kerangka zeolit, akan menyebabkan meningkatkan mobilitas pembawa muatan dari zeolit sehingga konduktivitas listrik zeolit menjadi tinggi. Hasil ini telah dibuktikan oleh Sriwahyuni (2014) yang melakukan pengujian sifat listrik dari zeolit yang dihasilkan, dengan penambahan larutan $\mathrm{NaAlO}_{2}$ dan tanpa penambahan $\mathrm{NaAlO}_{2}$. Nilai konduktivitas tertinggi diperoleh dari sampel zeolit pada penelitian ini dengan lama waktu peleburan 2 jam dengan nilai $2,4 \quad 10^{-6} \mathrm{~S} / \mathrm{cm}$.

\section{KESIMPULAN}

Lama waktu peleburan memberikan pengaruh penting dalam proses pembentukan zeolit sintetis.Variasi waktu pada proses peleburan $\mathrm{NaOH}$ dengan temperatur $750{ }^{\circ} \mathrm{C}$ dan menggunakan $\mathrm{NaAlO}_{2}$ sebagai media kristalisasi menghasilkan jenis zeolit yang berbeda. Peleburan selama 1 jam menghasilkan sodalit $(2,7 \%)$, lezurit $(47 \%)$, katoit $(29,4 \%)$, megakalsilit (6,6\%), kuarsa $(2,7 \%)$ dan kristobalit (4,2\%). Peleburan selama 2 jam menghasilkan sodalit $(43,1 \%)$, leusit $(34,7 \%)$ dan kalsilit $(22,2 \%)$. Peleburan selama 3 jam menghasilkan sodalit $(66,6 \%)$ dan bohmit $(33,4 \%)$. Peleburan selama 4 jam menghasilkan sodalit $(7,1 \%)$, nosean $(56,9 \%)$ dan katoit $(36,0 \%)$. Zeolit sintetis berdasarkan nilai konduktivitasnya berada pada rentang nilai semikonduktor. Zeolit dengan lama waktu proses peleburan 2 jam memiliki nilai konduktivitas listrik yang lebih tinggi dibandingkan sampel lain yaitu sebesar $2,410^{-6} \mathrm{~S} / \mathrm{cm}$. Waktu peleburan yang optimum digunakan pada proses peleburan adalah 3 jam. Nilai konduktivitas listrik dari zeolit yang dihasilkan semakin meningkat dengan kenaikan frekuensi. Konduktivitaslistrik zeolit yang dihasilkan tidak bergantung secara linier dengan waktu peleburan.

\section{DAFTAR PUSTAKA}

Auerbach, S., Carrado, K., Dutta, P., Hand Book of Zeolite Science and Technology, Marcel Dekker, Inc., New York, 2003.

Belviso, C., Francesco, C., Antinio, L., and Saverio, F., Zeolites Synthesis from Coal Fly Ash at Low Temperature Using Seawater for Crystalization, (CCGP journal, 2009) Vol. 1, UK CAER and ACAA, hal. 8-13.

Bukhari, S. S., Behin J., Kazemian, H. danRohani, S., Conversion of coal fly ash to zeolite utilizing microwave and ultrasound energies: A review, Fuel, Vol. 140, 250-266 (2014).

Chang, H.,L. dan Shih, W.H., A general Method for The Conversion of Fly Ash into Zeolitesan Ion Exchange for Cesium, (Industrial Engineering Chemical Research, 1998), Vol. 37, hal. 71-78.

Chetam, D.A., Solid State Compound, Oxford University Press, Oxford,1992.

Hamdan, H., Introduction to Zeolite Synthesis, Characterization and Modification, University Technologi of Malaysia (UTM), Malaysia, 1992.

Izci E. dan Izci A., Dielectric Behavior of the Catalyst Zeolite NaY, Turk J Chem, 31, 523-530, (2007).

Kalogeras, I. M., Electrical Properties of Zeolitic Catalyst, Defect and Diffusion Forum, Vol. 164 pp. 1-36, (1998).

Lestari T. dan Muttaqin, A., Pengaruh Air Laut Terhadap Zeolit Sintetis Dari Bottom Ash Melalui Proses Alkali Hidrotermal, (Jurnal Fisika Unand, 2015) Vol. 7, No. 1, hal.1927.

Londar, E., Hamzah, F., Nurul, W., Pengaruh Karbon Terhadap Pembentukan zeolit dari Abua Dasar dengan Metode Hidrotermal Langsung, (Jurnal Kimia ITS, FMIPA ITS, 2010), hal. 1-13. 
Nikmah, R, A., Pengaruh Waktu dan perbandingan Si/Al Terhadap Pembentukan Zeolit A dari Abu Dasar Bebas Karbon dari PLTU PT. IPMOMI dengan Metode Hidrotermal, (Jurnal Zeolit Indonesia, 2008), Vol. 7, No. 1. Hal. 42-52.

Ojha, K., Narayan, C.P., dan Amar, N, S., Zeolite from Fly Ash, Synthesis and Characterization, (Chemical Engineering Journal, 2004). Vol. 112. Hal. 109-115.

Oktaviani, Y. dan Muttaqin, A., Pengaruh Temperatur Hidrotermal Terhadap Konduktivitas Listrik Zeolit Sintetis dari Abu dasar Batubara dengan Metode Alkali Hidrotermal, (Jurnal Fisika Unand, 2015) Vol. 4, No. 4, hal.358-364.

Sari, N. K, "Pengaruh Waktu Sonikasi terhadap Konduktivitas Listrik Zeolit Berbahan Abu Dasar Batubara Menggunakan Metode Peleburan Alkali Hidrotermal", Skripsi S1, Universitas Andalas, 2016.

Smallman, R. E. dan Bishop, R. J., Metalurgi Fisik Modern dan Rekayasa Material, Edisi Keenam, (Erlangga, Jakarta, 2000).

Sriwahyuni, N, "Pengaruh Temperatur Peleburan Alkali terhadap KonduktivitasListrik Zeolit dari Bahan Abu Dasar Batubara dengan Metode Peleburan Alkali Hidrotermal", Skripsi S1, UniversitasAndalas, 2014.

Waleza, R, J. dan Muttaqin, A., 2015, PengaruhWaktu Refluks terhadap KonduktivitasListrik Zeolit Sintetik dari Abu Dasar, Jurnal Fisika Unand, Vol. 4, No. 4, hal. 17-23.

Yanti, Y, "Sintesis Zeolit A dan Zeolit Karbon Aktif dari Abu Dasar PLTU Paiton dengan Metode Peleburan", Tesis S2, Institut Negeri Surabaya, 2009.

Xu, R., Pang, W., Yu, J., Huo, Q. dan Chen, J., Chemistry of Zeolites and Related Porous Materials: Syintesis and Structure, (John Wiley \& Sons (Asia), Singapore, (2007). 